\title{
O GÓTICO E O DISTÓPICO SE ENTRELAÇAM: SEXUALIDADE E O CONTROLE DO CORPO FEMININO EM O CONTO DA AIA E OS TESTAMENTOS DE MARGARET ATWOOD ${ }^{1}$
}

Alice de Araujo Nascimento Pereira (UFF)

Recebido em 09 jan 2020. Alice de Araujo Nascimento Pereira é Mestre em Aprovado em 24 abr 2020. Literaturas de Língua Inglesa (UERJ). Doutoranda em Literatura Comparada (UFF) e Professora do Ensino Básico, Técnico e Tecnológico (IFF). "Necropolítica, patriarcado e o valor da vida humana nas distopias" (REVELL/UEMS). "A infertilidade como metáfora em The children of men de P.D. James (Anais da Abralic 2019). Lattes: http://lattes.cnpq. br/8193270402801504 E-mail: aliceanp6@gmail.com

Resumo: O gótico é muitas vezes tido como um gênero escapista e sentimental, com seus castelos mal assombrados, fantasmas e donzelas em perigo. No entanto ele reflete dilemas morais e políticas de momentos históricos específicos: as convulsões pós Revolução Francesa e as transformações sociais do período Vitoriano. Essas narrativas exploram os medos profundos da psique humana, problematizam as relações com o passado, investigam a fragmentação da identidade e questionam relações de poder. Ao longo do século $X X$, o gótico retornou intertextualmente, para novamente negociar

1 Título em inglês: "The gothic and the dystopic intertwine: sexuality and the control of women's bodies in the Handmaid's tale and The testaments by Margaret Atwood". 
ansiedades contemporâneas, diluído muitas vezes em outros gêneros e diversas mídias. Outro gênero que lida com questões similares é a distopia. Os romances O conto da aia e Os testamentos de Margaret Atwood são distopias em que há um regime autoritário teocrático cristão cujo foco central é o domínio do corpo feminino e o controle da reprodução e da sexualidade. Tais questões também eram centrais na literatura gótica. Nesse artigo pretendemos identificar e analisar os elementos do gótico nas obras de Atwood e compreender como a distopia e o gótico dialogam entre si e revelam críticas ao real.

Palavras-chave: gótico; distopia; Margaret Atwood; sexualidade; corpo feminino.

Abstract: The gothic genre is often considered escapist and overly sentimental, with its haunted castles, ghosts and damsels in distress. Nonetheless, it reflects moral and political dilemmas of specific historical moments: the upheaval post French Revolution and the social transformations in the Victorian period. These narratives explore the deepest fears in human psyche, problematize our relationships with the past, investigate the fragmentation of identity and question power relations. Throughout the twentieth century the gothic has returned intertextually, again to negotiate contemporary anxieties, many times distilled in other genres and diverse types of media. Another genre that deals with similar issues is dystopia. The novels The handmaid's tale and The testaments by Margaret Atwood are dystopias where there is an authoritarian theocratic Christian regime of which the focal point is the domination of women's bodies and the control over reproduction and sexuality. These issues are also central within gothic literature. In this article we aim at identifying and analyzing the gothic elements in Atwood's works and understanding how dystopias and the gothic establish dialogue and reveal a critique of the real.

Keywords: gothic; dystopia; Margaret Atwood; sexuality; women's bodies. 
Florestas densas e escuras, castelos medievais decadentes, correntes sendo arrastadas, assombrações de causar arrepio e belas donzelas enclausuradas. Essa iconografia é facilmente reconhecida como imagens de um gênero narrativo específico: o gótico. Associamos esse gênero principalmente às histórias de fantasmas, casas mal-assombradas, criptas, vampiros e monstros; narrativas que causam medo, mas também excitação, ao mexerem com o temor e curiosidade sobre o desconhecido, sobrenatural e o inexplicável, já que mudanças históricas, sociais e culturais renovaram os elementos associados ao gótico. David Punter resumiu algumas características no livro editado por ele: A new companion to the gothic, com artigos trazendo diversas contribuições acerca do tema. As narrativas desse gênero falam de fantasmas, maldições, figuras míticas e tentam invocar espectros; além disso, o gótico fala incessantemente de machucar o corpo e das feridas, referindo-se ao trauma, que recentemente vem sendo estudado nas suas dimensões individuais e coletivas (PUNTER, 2012, p.2). Os desenvolvimentos científicos, debates filosóficos e o contexto histórico foram igualmente relevantes para marcar as convenções da literatura gótica desde seu princípio no meado do século XVIII. Devemos enfatizar a força perturbadora de conceitos que influenciaram o gênero como seleção natural e o inconsciente humano, cujos modelos pré-Freudianos apontavam para um sujeito fragmentado pela descontinuidade e profundamente alienado de si mesmo (HURLEY, 1996, p.6), da mesma maneira a presença da dualidade humana, com as oposições entre corpo e mente e razão versus desejo (BOTTING, 2005, p.12). Ademais, esses debates identificavam o bestial dentro do humano $(2005, p .8)$, por 
isso a presença do duplo em muitas obras góticas revela faceta sombria debaixo do comportamento considerado apropriado como em Dr. Jekyll and Mr. Hyde de Robert Louis Stevenson. Tais questões da identidade instável e das inquietações acerca da natureza humana foram sendo atualizadas, expandidas e revistas, tratadas por outros gêneros que, como o gótico, afastaramse da representação fidedigna do real. Ainda hoje elementos do gótico são utilizados em outros gêneros, tornando-o ainda atual, como, por exemplo, na ficção científica, no romance de aventura, na literatura modernista e no horror; os temas góticos foram transformados e deslocados por diferentes ansiedades culturais (BOTTING, 2005, p.9). Segundo Julian Wolfreys é isso que torna o Gótico mais assombroso: ele promete sempre retornar, modificando-se e assumindo novas e inquietantes formas (2002, p.10). O inquietante no sentido freudiano é uma ferramenta de análise para investigar o gótico, pois para ele a sensação do unheimlich ao prometer uma realidade comum e depois a ultrapassa, podendo multiplicar e exacerbar aquilo que causaria inquietação nas experiências vividas (FREUD, p.278).

A Inglaterra do pós Revolução Francesa foi o berço da literatura gótica, cujos grandes expoentes em um primeiro momento foram Horace Walpole, Ann Radcliffe, Mary Shelley e Matthew Lewis. Esses autores escreveram obras centradas no sobrenatural, na luta do Bem contra o Mal e nas desventuras aterrorizantes dos seus personagens. Fred Botting teoriza que o gótico apareceu na obscuridade que assombrou a moralidade e a racionalidade da época, encobrindo os êxtases do idealismo e individualismo Românticos (BOTTING, 2005, p.1), ou seja, refletiam conflitos 
morais e sociais de um momento histórico turbulento. Mais tarde, Bram Stoker, Oscar Wilde e Henry James também escreveram importantes textos do gênero, respondendo de certa forma às questões da época Vitoriana. Nesse contexto mais urbano e moderno, não era mais o castelo fantasmagórico que causava o horror, mas sim o mundo interior de culpa, ansiedade, desespero e da interrogação acerca dos limites incertos entre liberdade de imaginação e conhecimento humano (2005, p.7). No século XX o gênero continuou a florescer e se diversificar, aparecendo de maneira mais difusa. Recentemente, outras mídias também se apropriaram dessas imagens para construir narrativas góticas atualizadas - através de paródias, reescritas, alusões e adaptações na televisão e no cinema.

O gótico tem reemergido ciclicamente em períodos de distensão cultural, "para negociar as ansiedades que acompanham as crises e transformações sociais e epistemológicas" (HURLEY, 1996, p.5, tradução nossa). Pretendemos nesse artigo traçar alguns pontos confluentes entre o gótico e outro gênero que de forma semelhante negocia essas crises e convulsões políticas e sociais: a distopia. Mais especificamente, tentaremos identificar e analisar os elementos e referências góticas nas obras $O$ conto da aia (1985) e Os testamentos (2019) de Margaret Atwood, focando nas questões do corpo e sexualidade feminina, temas importantes nas narrativas góticas e centrais nas obras investigadas aqui.

Assim como o Gótico, foi na Grã Bretanha que apareceram alguns dos mais importantes romances do gênero distópico: 1984, de George Orwell e Admirável mundo novo, de Aldous Huxley. A distopia também se disseminou pelo mundo anglófono 
e por diversas mídias, refletindo ansiedades globalizadas, ligadas às tecnologias, massificação da cultura, migração, violência urbana, crises ambientais e às desigualdades intrínsecas acarretadas pelo sistema capitalista. Primeiramente, devemos fazer algumas considerações teóricas para entender como esses gêneros dialogam. De acordo com Lyman Tower Sargent, as distopias são obras onde se descreve em detalhes uma sociedade que não existe localizada em um tempo e lugar que o autor pretendia que o leitor contemporâneo acreditasse ser consideravelmente pior que a sua (SARGENT, 1994, p.9). Já M. Keith Booker define literatura distópica como aquela que se situa como oposto absoluto ao pensamento utópico, um aviso contra suas potenciais consequências negativas (BOOKER, 1994, p.3). Maria Varsam argumenta que para determinar se um texto é ou não distópico, em oposição ao texto utópico, é mais importante atentar para a identificação que o leitor deve estabelecer com o protagonista/narrador, sendo seu desejo por um mundo melhor o que o distingue dos outros na sociedade distópica e que gera o conflito central (VARSAM, 2003, p.205). A efetividade do autor em criar essa identificação pode indicar o quanto a narrativa é bem-sucedida em inquietar seu público. Embora muitos considerem essas definições insuficientes, elas bastarão para os fins deste artigo, no qual nos deteremos mais em questões temáticas e elementos específicos. Em geral, a distopia apresenta um tom pessimista e mórbido, delineando contextos sombrios e sociedades sob regimes antidemocráticos, colocando uma lente de aumento sobre as questões problemáticas do presente ao projetá-las no futuro. A distopia é caracterizada pelo exagero, 
assim como o Gótico, segundo Botting, significa a escrita do excesso (2005, p.1), isso é, ambos trabalham utilizando metáforas, metonímias e hipérboles para ressaltarem as inquietações sobre o real.

As experiências coletivas traumáticas do século $X X$, como guerras mundiais, crise nuclear, desastres ambientais, imperialismo, terrorismo e convulsões sociais tornaram a sensação de medo coletivizado algo permanente, silencioso, diluído no cotidiano. Explorar o medo gerado por essas perturbações é algo que as distopias têm em comum com as narrativas góticas. Nosso senso universal de medo foi intensificado pela extrema rapidez da capacidade destrutiva da modernização (CLAEYS, 2017, p.9). A ideia de que a tecnologia, a ciência, os avanços sociais e a democracia liberal, valores que dominaram os discursos no século $X X$, nos levariam a uma sociedade harmônica, desenvolvida e justa não parece corresponder a nossa realidade empírica. Para Keith Booker, a literatura distópica trata justamente de responder e investigar esses conflitos e problematizações, não tanto numa tentativa de prever o futuro como o senso comum inúmeras vezes acredita, porém sim de compreender o presente:

Ao mesmo tempo, a literatura distópica também consiste numa crítica às condições e aos sistemas políticos existentes, seja pelo exame crítico das premissas utópicas nas quais essas condições e sistemas se baseiam ou através de uma extensão imaginária dessas condições e sistemas em contextos diferentes que mais claramente revelam suas falhas e contradições. (BOOKER, 1994, p.3, tradução nossa) 
Muitas vezes o gótico foi tido como escapismo por utilizar de elementos fantasiosos e estabelecer tom melodramático e sentimental, no entanto, o Gótico mantinha uma relação próxima com as questões de construção nacional e organização social, que ocasionalmente preconiza problemas sociais além de se preocupar em formar consciência social (PUNTER, 2012, p.4). Um dos aspectos do gótico tratado pelos escritores do período inicial baseia-se na contradição entre os ideais iluministas, que supostamente trariam o progresso e desenvolvimento econômico, e as pretensões conservadoras de se manter o status quo. (CARNEIRO, 2019, p.48), ou seja, refletiam as tensões características de seu período. Outro ponto em comum com as distopias é o caráter de advertência contra os perigos reais no presente, algo que as distopias salientam justamente para alertar seus leitores. A respeito disso, Botting defendeu que: "os romances góticos frequentemente adotam uma estratégia de precaução, alertando para os perigos das transgressões sociais e morais, apresentando-as em suas formas mais ameaçadoras e obscuras" (1996, p.5, tradução nossa). Da mesma maneira, romances distópicos também são profundamente conectados com os contextos históricos, tanto o presente quanto o passado. A obra de Atwood exemplifica essa ligação e se encaixa naquilo que Maria Varsam chama de distopia concreta, isso é, ela extrapola a partir de eventos reais, através dos quais transmite sua crítica e alerta (VARSAM, 2003, p.208). Não só porque o regime de Gilead prega um retorno aos valores do passado (ainda que esse passado seja mais idealizado do que baseado no real) materializado numa sociedade hierarquizada e que rejeita o uso de algumas tecnologias, mas porque as referências da trama estão no passado 
histórico real. Atwood ressaltou no seu artigo para o The New York Times que as questões da escravidão, de queimas de livros, os roubos de bebês na ditadura na Argentina e programas de aumento da natalidade feitos pelos Nazistas alemães foram alguns dos acontecimentos históricos inspiraram sua escrita (2017b, s/p). Além disso, o livro, publicado em 1985, refletia as ansiedades a respeito do conservadorismo protestante que penetrava a política americana naquele momento e já crescia a preocupação com a degradação do meio ambiente por conta da superexploração dos recursos naturais, ambos temas cruciais na narrativa de Atwood.

Embora $O$ conto da aia e Os testamentos não tratem da temática sobrenatural em seus enredos, há diversos elementos que fazem alusão às imagens e a atmosfera gótica. O romance $O$ conto da aia é uma distopia de sucesso que não deixou de ter novas edições desde sua primeira publicação. Nele, a narradora Offred nos conta sua vida como aia na República de Gilead, que substituiu os Estados Unidos após sua dissolução. O governo estabelecido é teocrático, totalitário e fundamentalista cristão, baseado nos valores do puritanismo do século XVII. Após desastres ambientais causarem queda brusca de fertilidade, as mulheres ainda férteis são forçadas a ter relações sexuais com membros da classe dominante, os Comandantes, cujas esposas têm dificuldade para engravidar. Nessa sociedade, as mulheres perdem suas liberdades e grande parte dos seus direitos civis, políticos e sexuais, dependendo da classe a qual pertencem. Além das aias, há as Esposas dos Comandantes; as Marthas, que fazem o serviço doméstico das residências mais abastadas; as Econoesposas, que são as mulheres casadas de classes mais baixas; as Tias, mulheres responsáveis 
pela organização do sistema das aias e de seu treinamento, e as Não-mulheres, aquelas que eram consideradas transgressoras e/ ou não úteis ao sistema, sendo enviadas para campos de trabalho nas chamadas colônias, onde limpariam lixo tóxico até a morte. As aias perdem seus próprios nomes e são destituídas de identidade: elas servem para procriar, como Offred diz: "somos úteros de duas pernas, apenas isso: receptáculos sagrados, cálices ambulantes" (ATWOOD, 2017a, p.165).

Para que possam gerar uma prole, as aias e os Comandantes devem ter relações sexuais num ritual mensal, na presença das Esposas dos Comandantes. Tal ritual, que chamam de noite da Cerimônia, é inspirado por uma passagem bíblica que se encontra no livro do Gênesis, cujos versículos servem de epígrafe do romance e que é lido antes da Cerimônia. Na passagem, Raquel não consegue ter filhos com seu esposo, Jacó, então pede que ele deite com sua serva Bila, pois assim Raquel teria filhos através da outra mulher. Offred (of = de, então seu nome é literalmente 'de Fred') foi separada de seu marido e de sua filha, dos quais não tem notícias, para servir na casa do Comandante Fred e sua esposa, Serena Joy. Ao longo da narrativa, Offred tem um caso amoroso com Nick, motorista do casal. Ela também descobre que existe um grupo rebelde que tenta lutar contra o regime, chamado Mayday. Ao final, um carro chega para levá-la embora, mas não sabemos exatamente para onde.

A continuação d'O conto da aia, Os testamentos, foi publicada em 2019. A narrativa transcorre 15 anos após os acontecimentos do primeiro livro. Embora Gilead se mantenha, o peso da corrupção e as disputas de poder começam fazer o regime ruir. Dessa vez, temos três perspectivas diferentes: a de Tia Lydia, que tivera um papel 
importante na vida de Offred e que tem uma posição privilegiada em Gilead; a da filha de Offred, Agnes, que permanecera em Gilead e fora criada como filha de uma família da elite, crescendo numa sociedade misógina e opressora; e Daisy, filha que Offred teve com Nick, mas que vive no Canadá sem ter ideia da sua origem. Cada uma narra sua trajetória até que seus destinos se cruzam e elas têm um papel importante da derrocada de Gilead.

Para Idley Cavalcanti, distopias centradas no domínio patriarcal sobre as mulheres como as de Atwood: "desenham infernos patriarcais de opressão, discriminação e violência contra mulheres, mapeando assim a sociedade contemporânea" (2002, p.247). Essas distopias evidenciam que a mulher tem sido constituída como uma entidade negativa "definida apenas por falta, suas virtudes mesmas só podem se afirmar em uma dupla negação, como vício negado ou superado" (BOURDIEU, 2010, p.37). A mulher é então definida por sua alteridade, considerada inferior ao homem: objetificada e desumanizada, servil. Desse modo, a ela tudo é negado exceto cumprir os papéis que the são reservados, sempre em relação a um homem: o de esposa, filha, mãe. A ideologia que é basilar na República de Gilead é a sujeição das mulheres, naquele contexto sendo categorizadas, hierarquizadas, disciplinadas e coisificadas para servirem aos interesses do regime teocrático fundamentalista cristão.

Nos romances de Atwood, no qual vemos um governo fundamentalista protestante, podemos averiguar que: "a cultura cristã, que tolera o sexismo e a dominação masculina, inspira as formas como aprendemos tudo sobre os papéis dos gêneros nesta sociedade" (HOOKS, 2019, p.153). Essa cultura cristã, outrossim, é 
bastante presente nas narrativas góticas e inclusive os monastérios e conventos são cenários típicos desse mundo ficcional e o medo dos demônios era recorrente, bem como menções ou comparações de quem desviava do comportamento socialmente aceito com o Diabo. Entretanto, não eram somente os seres sobrenaturais que cometiam as crueldades contra os heróis e heroínas dessas histórias. Nas narrativas góticas tradicionais, a tirania masculina, um tema recorrente, configura-se em: "uma conduta perversa e que segue uma lógica individual peculiar em que personagens mulheres tornamse "moeda de troca'" (CARNEIRO, 2019, p.51). A tirania masculina é a própria raison d'étre de Gilead e o valor de "troca" das mulheres depende da sua capacidade de gestar ou da sua posição em relação à um homem: seja pai ou marido. Segundo Claeys, a desumanização é a essência da vida das aias (2017, p.476), pois seu potencial de gerar uma vida é o que as define e as aprisiona, ao mesmo tempo. Vemos que Offred constantemente reitera sua condição de não humana com diversas comparações: "somos úteros de duas pernas, apenas isso: receptáculos sagrados, cálices ambulantes” (ATWOOD, 2017a, p.165), e antes da noite da Cerimônia: "Espero, lavada, escovada, alimentada, como um porco premiado" (2017a, p.85). Estar na condição de aia é ser uma coisa, não uma pessoa.

No entanto, para justificar o privilégio masculino que os permite controlar os corpos das mulheres, o regime necessita tirar dos homens alguma responsabilidade e fazer com que as mulheres se compadeçam e até se culpem: "Homens são máquinas movidas a sexo, dizia Tia Lydia, e não muito mais. Eles querem apenas uma coisa. Vocês têm que aprender a manipulá-los para o bem de si mesmas" (ATWOOD, 2017a, p.174). Igualmente, são também retratados 
como caçadores, como competidores que precisam batalhar por um prêmio. O Comandante, ao comentar o comportamento das mulheres antes de Gilead, diz: "O sexo era fácil demais. Qualquer um podia apenas comprá-lo. Não havia nada pelo que trabalhar, nada por que lutar" (2017a, p.250). É uma contradição básica do sistema patriarcal: retratar os homens como irracionais apenas em relação ao sexo, porém perfeitamente racionais em todas as outras áreas da vida. Uma tradição bastante antiga, porém prevalente no final do século XIX "identifica as mulheres como entidades definidas e presas em seus próprios corpos, em contraste com os homens, que seriam governados por racionalidade e capazes de transcender sua corporalidade" (HURLEY, 1996, p.119). O regime de Gilead se utiliza da potência genésica das mulheres, aprisionando-as nos próprios corpos, alienando-as a ele:

Minha nudez já é estranha para mim. Meu corpo parece fora de época. Será que realmente usei trajes de banho, na praia? Usei, sem pensar, entre homens [...] Vergonhoso, impudico. Evito olhar para baixo, para o meu corpo, não tanto porque seja vergonhoso ou impudico, mas porque não quero vê-lo. Não quero olhar para uma coisa que me determina tão completamente (ATWOOD, 2017a, p.78, itálico da autora)

A protagonista ressignifica seu olhar sobre o corpo feminino de maneira geral após se tornar uma aia. Podemos averiguar isso na cena em que Offred se sente entediada e lembra de andar por galerias de arte e observar pinturas do século XIX que retratavam mulheres nuas e ociosas. Ela reflete que costumava achar essas imagens eróticas, mas agora pensava que mostravam "objetos que não estavam em uso [...] mas talvez o tédio fosse erótico quando 
são as mulheres que o fazem, para os homens" (2017, p.85). As mulheres passivas pintadas naqueles quadros têm pontos em comum com as personagens das narrativas góticas: a iconografia da donzela inativa, que antecede o Gótico, mas que é invocada por ele. Essa imagem ainda se faz presente nos anúncios e propagandas de revistas e na televisão, por exemplo. De certa forma, as aias ainda remetem a tal imagem: ainda que vestidas, elas vivem uma vida de ociosidade, apenas aguardando as noites em que ocorreria a Cerimônia, metaforicamente despidas de qualquer agenciamento.

Em Os testamentos, Agnes frequenta a escola para as meninas das famílias de elite de Gilead, onde a educação é voltada para religião e para os afazeres que elas teriam quando se tornassem Esposas, como o bordado e jardinagem. As professoras são as Tias. Em diversas passagens podemos verificar perspectivas sobre o corpo da mulher sendo retratado por aquela sociedade como repulsivo, maléfico e ameaçador. A socialização de Agnes é toda voltada para ver o corpo feminino como um fardo. Ela coloca que: "o corpo da fêmea adulta era uma grande arapuca. Se houvesse um buraco, com certeza algo seria enfiado nele e depois outra coisa sairia dele [...] acabei sentindo que estaria melhor sem ele" (ATWOOD, 2019, p.95). Com essa fala ela também demonstra que o corpo feminino não é sujeito e sim objeto das ações de outrem: ele é uma armadilha inescapável. Os espaços vastos e aprisionadores que aparecem regularmente no gótico como castelos, monastérios e prisões de fato podem ser lidos como metáforas para as vidas das mulheres dentro do sistema patriarcal (PUNTER, 2012, p.458). As prisões metafóricas das narrativas góticas representavam os encarceramentos impostos às mulheres. No Gótico, a torre do 
castelo ou a masmorra eram os locais do aprisionamento das mulheres; já na distopia, os regimes totalitários tornam o próprio corpo feminino um lugar de clausura, além de os próprios regimes já serem prisões por si mesmos.

Numa das aulas de Religião ministradas pelas Tias para as meninas, Agnes relata que um dia contaram a história da Bíblia que seria muito importante para que elas entendessem o papel que deviam desempenhar naquela sociedade: a da Concubina Cortada em Doze Pedaços, sobre uma mulher que fora violentada e morta após desobedecer ao seu dono e tentar retornar para casa. Uma das Tias alerta às meninas que: "A mulher deveria honrar o homem que tem direito sobre ela, ela acrescentou. Deus sempre dava o castigo adequado ao crime" (2019, p.91). A amiga de Agnes, Becka, que havia sofrido abuso sexual do próprio pai entra em pânico ao escutar essa história e tenta suicídio algum tempo depois.

As mulheres representadas no gótico estavam em dois polos aparentemente opostos: ou elas são retratadas como donzelas pueris ou como sedutoras e vingativas. Quanto às primeiras: "críticas feministas do gótico se dividem em relação a se as heroínas são submissas e logo, modelos de bondade patriarcalmente definidas para seus leitores" (PUNTER, 2012, p.458, tradução nossa). Já o segundo tipo, a ideia de mulheres traiçoeiras e sensuais é uma ferramenta de controle e silenciamento que em Os testamentos Agnes vê da seguinte maneira:

Seja lá quais fossem nossos traços e características, éramos sempre sedutoras arapucas, éramos os ensejos inocentes pela própria natureza, 
podíamos deixar os homens bêbados de luxúria, levando-os a vacilar, tropeçar e acabar caindo. (ATWOOD, 2019, p.17-18)

Porém é importante considerar que a tarefa da heroína gótica clássica é escapar do castelo onde foi feita prisioneira, e ao fazer isso, comandar sua desmistificação, um processo que requer destruição violenta, e tomar posse da fortuna e linhagem que o vilão tomou roubar para si mesmo (PUNTER, 2012, p.463). A ideia da clausura é fundamental no gótico, como é nas distopias, pois elas justamente retratam regimes fechados e personagens aprisionados que buscam uma saída:

Com frequência temos espaços físicos (habitados por heroínas) que nos remetem à ideia de clausura e encarceramento. Os subterrâneos, as galerias, os mosteiros e a própria casa revelam imagens opressoras, numa clara alusão à opressão impingida pelo poder patriarcal sobre a mulher. (CARNEIRO, 2019, p.56)

O aprisionamento feminino acontece em diversos níveis e toma várias formas na República de Gilead: a vestimenta, a casa dos Comandantes, o Centro Vermelho, onde ocorria o treinamento das aias; o Jezebel's, o prostíbulo para os Comandantes; as Colônias, Gilead em si, e os próprios corpos - todos são prisões para as mulheres. A separação das mulheres em castas acaba confinandoas em suas vestimentas e reitera a imobilidade das classes sociais: as Esposas de azul, Marthas usando verde e as Tias de cinza. As aias, especificamente, vestidas com suas roupas vermelhosangue, usam toucas brancas e véus: "as toucas [...] são destinadas a nos impedir de ver e de sermos vistas" (ATWOOD, 2017a, p.16). 
Por sentir-se enclausurada, Offred diz que se recusa a chamar o quarto onde ela dorme de seu (2017a, p.16) o quarto no $2^{\circ}$ andar remetendo ao tropo da donzela no alto da torre, com seu véu e vestido longo, esperando ser resgatada. A descrição da casa do Comandante Fred e Serena Joy também tem um caráter deslocado e gótico, Offred diz que a casa: "Do fim do período vitoriano, a casa é uma residência de família, construída para uma família rica e numerosa" (2017a, p.17). Porém o funcionamento do regime torna esses espaços sombrios, vazios e morbidamente silenciosos.

Já em Os testamentos, vemos que mesmo para as mulheres de classe mais alta como Agnes, a perspectiva do casamento era uma prisão. Ela estava noiva de um homem muito mais velho e de alto cargo em Gilead, porém o terror absoluto de uma relação sexual com ele the parecia insuportável. Ela contempla fugir de casa, mas sabe que não teria os meios para executar essa escapada e complementa: "O mundo estava infestado de homens que com certeza achariam tentadora uma menina desencaminhada, essas meninas seriam vistas como mulheres de moral dúbia" (2019, p.242). A solução que acaba se apresentando para ela é tornar-se uma Tia, alegando ter Vocação para tal. Após a morte da mulher que Agnes pensava ser sua mãe, Tabitha, a casa em que morava não era mais um local de afeto e segurança emocional, porém a perspectiva de um casamento em nenhum momento pareceu uma alternativa melhor para ela, podemos inferir que: "assim como nas narrativas góticas tradicionais, onde a casa era espaço de opressão e medo, também em Gilead notamos tais ocorrências" (CARNEIRO, 2019, p.55). A história que Tabitha contava para Agnes sobre como ela a havia adotado remetia aos contos de fada e imagens góticas, 
mas mascara a transgressão do sequestro das crianças promovido pela elite de Gilead, que separava as famílias como as de Offred:

Fui passear na floresta - dizia ela - e lá cheguei a um castelo encantado, onde havia um monte de menininhas presas, e nenhuma delas tinha mãe, e estavam todas elas enfeitiçadas pelas bruxas más. Eu tinha um anel mágico que abria o castelo, mas eu só podia resgatar uma menininha. (ATWOOD, 2019, p.20)

A sexualidade desempenha um papel importante nas ficções distópicas, pois se opõe ao coletivismo e ao utilitarismo da ideologia dominante, escapando, pelo menos esporadicamente, de regulação e controle. Nota-se então que sexualidade não pode ser analisada somente como fenômeno biológico nem como produto da psicologia individual, mas como questão social e política (RUBIN, 2007, p.157). É na sociedade vitoriana do século XIX, um momento de publicação de grandes obras góticas, que a sexualidade, para além do ato íntimo da relação sexual, fruto do livre-arbítrio dos envolvidos, passa a concernir à sociedade como um todo e “na junção entre 'corpo' e a 'população', sexo tornou-se o alvo central de um poder que se organiza em torno da gestão da vida" (FOUCAULT, 1988, p.138). Ou seja, a Ciência, a Psicologia, o Direito, a Sociologia juntamente com o Estado desenvolvem técnicas e instrumentos para estudar, compreender e regular a atividade sexual da população. Esses instrumentos e formas de controle são exacerbados nas distopias como nas de Atwood, pois servem aos interesses de governos antidemocráticos.

Não obstante, sexo e sexualidade também podem servir como forma de contestação e de afirmação de identidade individual. 
Os governos distópicos tendem a reprimir a sexualidade porque também é ela fonte potencial de poderosas energias subversivas (BOOKER, 1994, p.12). Segundo a análise de Thomas Horan, alguns dos grandes autores de ficção distópica apresentam a sexualidade como uma parte do Self que nunca pode ser totalmente apropriada, logo ela seria uma força para regeneração espiritual e política dentro do Estado totalitário (HORAN, 2007, p.314). Offred tem um caso com o motorista Nick e isso faz com que ela recupere um certo senso de ação, ela pondera: "Não o fiz por ele e sim inteiramente por mim mesma" e também que não definia aquilo como amor, mas que havia conseguido criar uma vida para ela mesma ali, apesar de tudo (2017a, p.320). Na obra mais recente de Atwood, Agnes e sua amiga Becka têm pânico da ideia de casar e da obrigação de manter relações sexuais. Elas haviam sido assediadas pelo pai de Becka, por essa razão, as jovens vão para o Ardua Hall, escapam da obrigação do matrimônio e logram estudar para eventualmente se tornarem Tias. Becka, que sofrera abuso sexual por parte de seu pai durante anos, disse às Tias que preferiria a morte ao casamento (2019, p.260). Para elas desfrutar da sexualidade, como Offred havia feito, não era uma alternativa de resistência, dentro das suas possibilidades, recusála foi uma maneira de alcançarem uma autonomia que talvez não obtivessem em outra posição naquela sociedade.

Devemos acrescentar que, segundo Hurley, o romance gótico típico representa: "a sexualidade como horripilante [e] a identidade como múltipla" (HURLEY, 1996, p.13, tradução nossa), como vemos em O Monge (1796), de Matthew Lewis, no qual Ambrosio cede à tentação de Mathilda, sucumbindo aos prazeres carnais até 
se apaixonar por sua própria irmã e raptá-la para satisfazer seu desejo. Podemos ver que tanto para os regimes totalitários das distopias quanto para a moralidade vitoriana do romance Gótico, a sexualidade era tida como ameaçadora quando desviava das prescrições sociais consideradas aceitáveis. Para Linda Gordon, a ideologia Vitoriana afirmava que as esferas do masculino e do feminino eram separadas, mas iguais: as mulheres, embora supostamente inferiores na aptidão intelectual, artística, econômica e física, eram tidas como moralmente superiores já que possuiriam a capacidade natural para maternidade (2002, p.11). Logo, qualquer sexualidade cujo fim não fosse reprodutivo é imoral e indesejável.

Outra perspectiva é de que o gótico muitas vezes reforçava a sexualidade normativa ao representar comportamentos como feminilidade agressiva e homossexualidade como monstruosas ou abomináveis, porém, mesmo dentro deste registro o gótico conseguiu multiplicar e, portanto, desestabilizar os significados da sexualidade (HURLEY, 1996, p.10-11). Por outro lado, de acordo com Botting, a feminização das práticas de leitura e do mercado literário foram vistas como perturbadores da sensibilidade doméstica e ao invocar um passado que o século XVIII percebia como bárbaro, parecia promover vício e violência, dando sinal verde para ambições egoístas, desejo sexual imoral e fora do dever familiar (1996, p.3). A ideia de que certas leituras podiam "perturbar a sensibilidade doméstica" ecoa no regime teocrático de Gilead, que vai mais além e proíbe toda e qualquer leitura às mulheres. Não por ser só uma distração no caminho do cumprimento do seu "destino biológico", mas porque a leitura é uma ferramenta de conhecimento e logo, contestação. 
Em Gilead, as mulheres servem para a procriação ou para satisfazer os desejos sexuais dos Comandantes, ou como mão de obra braçal não remunerada, nunca possuindo uma sexualidade própria. Por esse motivo, Offred reitera como as aias são úteros de duas pernas: a relação sexual possui um único fim que é gerar filhos. Para tia Lydia, é importante reiterar a necessidade de se ter filhos e inferiorizar aquelas que não o desejavam para convencer as aias da sua importância, então as Tias denigrem as mulheres que faziam uso de sua liberdade sexual antes do regime: "eram mulheres preguiçosas, dizia ela. Eram mulheres vagabundas" (2017a, p.138), ou seja, eram mulheres sem dignidade. Para Virginie Depentes, ainda hoje, o discurso que alega querer preservar a dignidade da mulher é utilizado justamente para "limitar a expressão sexual" (2016, p.80). Tia Lydia também enfatiza que a modéstia era característica essencial das mulheres, especialmente das aias: "ser vista - ser vista - é ser - a voz dela tremeu - penetrada. O que vocês devem ser, meninas, é impenetráveis" (2017a, p.41). Essa comparação de 'ser vista' com 'ser penetrada' - que faz uma clara alusão ao ato sexual - mostra como os homens seriam incontroláveis em seu desejo e as mulheres, uma distração indesejável que precisa se tornar invisível.

Se no passado eram as instituições religiosas que possuíam o poder político e econômico mais amplo, exercendo o controle da sexualidade através da moral cristã como instância da ideologia patriarcal, hoje é o Estado, que ratifica e reforça "as prescrições e proscrições do patriarcado privado com as de um patriarcado público, inscrito em todas as instituições encarregadas de gerir e regulamentar a existência cotidiana da unidade doméstica" (BOURDIEU, 2010, p.105). Ou seja, são as instituições políticas 
e econômicas que engendram e intensificam as assimetrias de poder entre os gêneros. Silvia Federici destrincha os antecedentes históricos desse processo em seu livro Calibã e a bruxa, provocações interessantes sobre a caça às bruxas, perseguição sistemática organizada pela Igreja Católica e pelos estados europeus entre os séculos XV e XVIII. Ela afirma que no processo de caça às bruxas foi essencial a proibição de formas não produtivas e não procriativas de sexualidade feminina, por serem consideradas demoníacas e antissociais, inclusive identificando a sexualidade das mulheres com a bestialidade (2017, p.346-347). Nesse tocante, Carneiro faz um interessante paralelo entre o romance gótico Os mistérios de Udolpho de Ann Radcliffe e $O$ conto da aia no tocante da relação entre controle da sexualidade e como isso influenciam na relação entre as mulheres:

Além do medo e da culpa, destacamos a relação de violência e ódio que se desenvolve entre as próprias personagens femininas, e isso se verifica tanto na narrativa de Radcliffe, como na narrativa de Atwood. Em ambas, as mulheres se rejeitam e se voltam umas contra as outras não só por serem vítimas de um sistema de troca entre homens poderosos, bem como pelo fato de que cada mulher possui desejos incontroláveis e reprimidos, ou seja, humilhar uma mulher significaria, nas entrelinhas, rejeitar aquilo que elas não podem ter, daí viverem sob a égide da religião e da família como forma de aplacarem seus desejos. (2019, p.54)

Controlar a sexualidade ganhou respaldo nas discussões médicas na época vitoriana já que as mulheres eram vistas como mais suscetíveis aos distúrbios mentais e de comportamento. Segundo Hurley, um dos pontos mais relevantes no Gótico do final do século 
XIX é que os distúrbios do corpo feminino eram indissociáveis do sistema reprodutivo feminino, então a sexualidade feminina aparece tanto como causa quanto como sintoma da desumanidade feminina. (HURLEY, 1996, p.120). Esse resgate do histórico do controle do corpo e da sexualidade femininos é importante para pensar no papel do tempo nas distopias e no gótico.

Embora as distopias sejam normalmente projeções do futuro, inúmeras vezes invocam o passado, tanto para tentar reconstruí-lo e entendê-lo, como vemos Winston tentar fazer em 1984, quanto como fonte nostálgica de tempos melhores. Atwood, no entanto ainda o usou de outra forma: a autora se inspirou em eventos reais passados para tecer as características dessa sociedade. Atwood afirmou que: "Eu não colocaria no livro eventos que não houvessem já acontecido no que James Joyce chama de o 'pesadelo' da história, nem uma tecnologia que não estivesse já disponível" (2017b, s.p.). Ao falar sobre sua obra e a influência da história sobre ela, Atwood afirmou que: "a maioria dos totalitarismos que conhecemos tentaram controlar a reprodução de uma forma ou de outra - limitando os nascimentos, demandando nascimentos, especificando quem pode casar com quem e de quem são os filhos" (2012, p.87, tradução nossa)

Essa busca pelo passado está presente nas: "atmosferas góticas - deprimentes e misteriosas - [que] têm repetidamente assinalado o retorno perturbador do passado sobre o presente" (BOTTING, 1996, p.1). Em Gilead também se busca por valores do passado, rejeitando a modernidade que veem como responsável pelos desastres ambientais que levaram à crise de fertilidade e a subsequente decadência da sociedade. Ao descrever a rua onde habita em Gilead, Offred a compara com fotografias antigas e diz 
"A rua é quase como um museu ou uma rua numa cidade modelo construída para mostrar a maneira como as pessoas costumavam viver" (2017a, p.34) apontando a tentativa de resgate do passado que o regime pretendia. Em Os Testamentos a busca de Agnes pelo passado que lhe foi ocultado persiste ainda na idade adulta. Em uma das poucas bibliotecas ainda existentes, a qual as Tias têm acesso no Ardua Hall, local em que residem, e onde ficam não só os livros proibidos, desde Jane Eyre à Paradise Lost, mas também os arquivos genealógicos contendo as informações sobre as famílias locais. Esses dados eram importante para que Tias e Comandante controlassem os casamentos, nascimentos e o paradeiros dos filhos e filhas das mulheres que se tornariam aias. O conhecimento do passado é um privilégio para poucos "os arquivos são o coração do Ardua Hall" (2019, p.23). Nesse sentido, o acesso ao passado como segredo a ser guardado também remete ao gótico, em que baús, diários, cartas e porões guardavam o desconhecido.

A escrita gótica frequentemente deixa os leitores incertos sobre se as narrativas estão descrevendo perturbação psicológica ou rebeliões mais amplas dentro da formulação da realidade e da normalidade (BOTTING, 1996, p.7). Já a distopia não deixa espaço para tal dúvida: ela é uma representação da experiência do indivíduo dentro de um contexto político social repressor. Há um diálogo entre o gótico e o distópico no que tange diversas questões, embora eles reflitam ansiedades distintas e percorram caminhos narrativos bem diferentes. Em $O$ conto da aia e Os testamentos podemos identificar traços que estabelecem uma intertextualidade com o gótico, tanto no tom quanto ao tema, atualizando o gênero dentro das novas dinâmicas de poder e ansiedades próprias do momento histórico. 
O controle do corpo e da sexualidade feminina é um ponto central nas obras de Atwood assim como foi na literatura gótica. O que a ideologia do patriarcado faz é negar às mulheres o poder sobre suas vidas, sobre seus próprios corpos e sobre os rumos das comunidades em que estão inseridas. Federici argumenta é que "resultante dos anos de propaganda e terror espalhou-se entre os homens as sementes de uma profunda alienação psicológica com relação às mulheres" (FEDERICI, 2017, p.340). O gótico e a distopia feminista tornam esses paradigmas mais óbvios ao deslocá-los do real. A literatura nos ajuda a perceber, afinal, que precisamos de uma erótica do ser fundamentada no princípio de que temos o direito de expressar desejo sexual e de encontrar no prazer sexual um ethos de afirmação da vida (HOOKS, 2019, p.136). Afirmar a vida, tornando-a menos assombrada pelo passado e mais fértil para o futuro.

\section{REFERÊNCIAS}

ATWOOD, Margaret (2012). In other worlds: SF and the human imagination. New York: Anchor Books.

_ (2017a). O conto da aia. Ana Deiró (Trad.). Rio de Janeiro: Editora Rocco, (2017b). "Margaret Atwood on what The Handmaid's tale means in the age of Trump". The New York Times. In: https://www.nytimes.com/2017/03/10/ books/review/margaret-atwood-handmaids-tale-age-of-trump.html Acesso em 18.Jan. 2018

(2019). Os Testamentos. Simone Campos (Trad.). Rio de Janeiro: Editora Rocco.

BOOKER, M. Keith (1994). The Dystopian Impulse in Modern Literature: Fiction as Social Criticism. Westpoint; Londres: Greenwood Press.

BOTTING, Fred (2005). Gothic. Londres; Nova York: Routledge. 
BOURDIEU, Pierre (2010). A dominação masculina. Maria Helena Kuhner (Trad.). Rio de Janeiro: Bertrand Brasil.

CARNEIRO, Fabianna (2019). "Releituras do gótico inglês setecentista no romance $O$ conto da aia". Aletria, Belo Horizonte, 29(2), 45-61.

CAVALCANTI, Ildney (2002). "A distopia feminista contemporânea: um mito e uma figura." In: Boletim do GT da ANPOLL: 'A Mulher na Literatura', 9. Florianópolis: UFSC.

CLAEYS, Gregory (2017). Dystopia: A Natural History - A Study of Despotism, Its Antecedents, and Its Literary Diffractions. Oxford: Oxford UP.

DEPENTES, Virginie (2016). Teoria King Kong. Márcia Bechara (Trad.). São Paulo: N-4 Edições.

FEDERICI, Silvia (2017). Calibã e a bruxa: mulheres, corpo e acumulação primitiva. Coletivo Sycorax (Trad.). São Paulo: Elefante.

FOUCAULT, Michel (1988). A história da sexualidade l: a vontade de saber. Maria Thereza da Costa Albuquerque e J A. Guilhon Albuquerque (Trad.). Rio de Janeiro: Edições Graal.

FREUD, Sigmund (2010). "O inquietante". In: Obras completas, vol. 14: História de uma neurose infantil ("O homem dos lobos"), Além do princípio do prazer e outros textos (1917-1920). São Paulo: Companhia das Letras, p.328-376. GORDON, Linda (2002). The moral property of Women: a history of birth control politics in America. Chicago: The University of Illinois Press.

HOOKS, Bell (2019). O feminismo é para todo mundo: políticas arrebatadoras. Ana Luiza Libânio (Trad.). Rio de Janeiro: Rosa dos Tempos.

HORAN, Thomas (2007). "Revolution from the Waist Downwards: Desire as Rebellion in Yevgeny Zamyatin's We, George Orwell's 1984 and Aldous Huxley's Brave New World". Extrapolation, Bronsville: The University of Texas Press, 48(2), 314-339.

HURLEY, Kelly (1996). The Gothic Body: Sexuality, materialism, and degeneration at the fin de siècle. Cambridge (UK): Cambridge UP.

McLAREN, Margaret A (2016). Foucault, feminismo e subjetividade. Newton Milanes (Trad.). São Paulo: Intermeios.

PUNTER, David (Ed.) (2012). A New Companion to The Gothic. Malden (MA): Blackwell. 
SARGENT, Lyman Tower (1994). "Three Faces of Utopianism revisited". Utopian Studies, Pensylvania: Penn State UP , 5(1), 1-37.

RUBIN, Gayle. (2007) "Thinking Sex: Notes for a Radical Theory of the Politics of Sexuality". In: AGGLETON, Peter; PARKER, Richard (Orgs.). Culture, Society and Sexuality. Londres e Nova York: Routledge.

VARSAM, Maria (2003). "Concrete Dystopia: Slavery and Its Others". In: BACCOLINI, Raffaella; MOYLAN, Tom (Orgs.). Dark Horizons: Science Fiction and the Dystopian Imagination. Nova York; Londres: Routledge.

WOLFREYS, Julian (2002). Victorian Hauntings: Spectrality, Gothic, the Uncanny and Literature. Basingstoke (UK): Palgrave. 